\title{
Prohibition of Advertising of the Advocate in Written or Visual Communication Tools
}

\author{
Fatma Alaslan \\ Yakin Dogu University, Faculty of Law, Lefkosa, Cyprus \\ E-mail: fatma.alaslan@neu.edu.tr
}

\begin{abstract}
Advertisement is promoting a good or service in order to increase the demand on that good or service. While advertising is suitable for some professions, it should be limited in terms of some professions. The profession of law is one of them.

On the one hand, the advocate's efforts to increase the demand on the service offered by advertising can be said to be incompatible with the honour of the profession, while on the other hand, it also poses the danger of creating an unfair completion among the members of the same profession. Therefore, those kind of activities should be limited. In the law of North Cyprus, the restriction regarding to these activities can be found in Article 13 of the 1981 Legislation. Similar regulations regarding to the prohibition of advertising can also be examined in Turkish law.

Those regulations set a limit to the advertising activities of the advocates, thus preventing the reliability and dignity of the profession being damaged. Therefore, this prohibition of advertising is fundamental both in terms of professional ethics and respectability of the profession.
\end{abstract}

Keywords: Advocate, Advertising, Prohibition of Advertising

DOI: $10.7176 /$ JSTR/6-04-03

\section{Avukatın Reklam Yasağı Teşkil Edecek Şekilde Yazılı veya Görsel İletişim Araçlarında Yer Alması}

\begin{abstract}
Özet
Bir mal veya hizmeti tanıtarak, o mal veya hizmetin sahip olduğu nitelikleri sergileme faaliyetlerinde bulunup, o mal veya hizmet üzerinde talep artırmaya yönelik faaliyetler reklam olarak adlandırılır. Reklam faaliyetinde bulunmak kimi meslekler için uygunken, bazı meslekler bakımından tartışmalı olabilir. Avukatlık mesleği de bu mesleklerdendir.

Avukatın, sunacağı hizmet üzerinde, reklam faaliyetlerinde bulunarak talep artırma yoluna gitmesi bir yandan meslek onuru ile bağdaşmazken, öte yandan aynı meslek mensupları arasında haksız rekabet tehlikesi yaratabilir. Dolayısıyla bu reklam faaliyetlerinin bir sınırı olmalıdır. Kuzey Kıbrıs hukukunda, 1981 Avukatlar Tüzüğü’nde avukatın reklam faaliyeti niteliği taşıyan davranışlarına ilişkin sınırlama, reklam yasağı başlığı altında 13. maddede 5 fikra halinde düzenlenmiştir. Türk hukukunda da avukatın reklam yasağına ilişkin benzer düzenlemeler söz konusudur.

Reklam yasağı teşkil eden kurallar sayesinde, avukatın reklam faaliyetlerine bir sınır konularak, mesleğin güvenilirliğinin, saygınlığının zedelenmesinin önüne geçilmiştir. Dolayısıyla reklam yasağı, hem meslek etiği açısından hem de mesleğin saygınlığı açısından oldukça önemlidir. Ancak reklam yasağının da belirli sınırlarının olması gerekmektedir. Zira avukatlar yapmış oldukları reklam faaliyetleriyle bir yanda kamuoyunu bilgilendirme, adalet bilinci yaratma, savunma hakkını hatırlatma gibi önemli sonuçların doğmasına vesile olmaktadırlar.
\end{abstract}

Anahtar Kelimeler: Avukat, Reklam, Reklam Yasağı. 


\section{Giriş}

Hukuki yardıma ihtiyacı olan bir kimsenin, yardıma ihtiyacı olduğu konuda kendisine daha fazla yarar sağlayacak bir avukatın hizmetinden faydalanması ancak avukatın mesleki faaliyetlerine ilişkin elde edeceği bilgilerle doğru orantılıdır. Bu sayede kişi doğru avukatı seçebilecektir. Avukatın tarafi olduğu bir dava hakkında kamuoyunu aydınlatmak üzere; bilgi vermesi, herhangi bir hukuk dergisinin, sair bir derginin veya basın yayın organının soracağı sorulara cevap vermesi, hukuki, siyasi veya başka bir alanda makale yazması ve yayımlaması şeklinde gerçekleştireceği davranışları avukatın mesleki bilgi ve becerisinin ortaya konulmasına aracı olacaktır. Böylece avukat, sunacağ yoluna giderek, iş temin edebilecektir. Hal böyle olunca, avukatın yukarıda belirtmiş olduğumuz davranışlarına reklam yasağı başlığı altında bir takım kısıtlamalar getirilmiştir. Tüm bu kısıtlamaların esas amacı, avukatın şahsi reklam yapmasının önüne geçilerek, avukatlık mesleğine mensup kişiler arasında meydana gelebilecek haksız rekabeti bertaraf etmektir.

Oysa, Türkiye ve Kıbrıs avukatlarınında bağlı olduğu, Avrupa'da Avukatlık Mesleğine İlişkin Temel İlkeler Tüzüğü ve Avrupada Avukatların Tabi Olduğu Meslek Kuralları içerisinde avukatın meslek etiğiyle, meslek onuruyla bağdaștığı müddetçe yazılı basın, radyo, televizyon, elektronik ticari iletişim araçları ve diğer vasıtalarla şahsi reklam yapabileceği belirtilmiştir. Şahsi reklam, barolar ve meslek örgütleri tarafından üyelerini kapsar şekilde yapılan kurumsal reklamlar dışında, avukatlık büroları ve avukatlar tarafından yapılan reklamlar olarak tanımlanmıştır. Dolayısıyla, meslek etiği ve onuruyla bağdaştığı müddetçe, görsel veya yazılı iletişim araçlarından faydalanarak, avukatlık bürolarının ve avukatların şahsi reklam yapmasının herhangi bir sakıncası olmadığını söyleyebiliriz.

Çalışmamızda Kuzey Kıbrıs hukuku ile Türk hukukunda avukatın görsel veya yazılı basında ne şekilde yer alması gerektiğine ilişkin açıklamalarda bulunarak, söz konusu kuralların daha esnek hale gelmesi halinde meydana gelebilecek faydaların veya sakıncaların üzerinde durulacaktır.

\section{Reklam Yasağı Kavramı}

Avukatların zaman zaman mesleki faaliyetlerini yerine getirirken ilgili oldukları davalar hakkında veya bunlara ilişkin mesleki faaliyetleri hakkında açıklamalarda bulunmaları ve bu açıklamalarıyla birlikte görsel veya yazılı basında yer almaları rastlanılan bir durumdur. Avukatların bu gibi hallerde dikkat etmeleri gereken bir takım davranışlar vardır. Bu davranışlarda bulunmama veya kaçınma halleri, reklam yasağı kapsamında ele alınmaktadır. Dolayısıyla, bu kurallara uyulmaması halinde avukatın reklam yasağına aykırı davrandığı sonucuna varılır.

Reklam, bir mal veya hizmetin muhatabına tanıtılmasıyla, satışın artırılması yöntemlerinden biridir (Onay, 2012, s.56; Özdemir, 2004, s.65; Peker, 2007, s.211). Reklam yasağ kitlelere tanıtarak, onlar üzerindeki talebi artırmak maksadıyla gerçekleştirilecek faaliyetlerin yasaklanmasıdır (Aslan, 2015, s.19; Aydın, 2013, s.382; Ersoy, 2004, s.229; Rumpf, 2010, s.161). Bir mal veya hizmet üzerine reklam yasağı konmuşsa, o mal veya hizmeti tanıtıp üzerinde talep yaratmak veya o mal veya hizmete ilişkin satışı arttırmak için faaliyetlerde bulunmak artık mümkün olmayacaktır (Güner, 2011, s.76; Yavaş, 2016, s.728).

Bazı meslek mensuplarının sunacağı hizmet niteliklerinin reklam vasıtasıyla muhataplarına ulaştırılması mümkündür. Ancak reklam faaliyetinin meslekin niteliği ile bağdaşması gerekmektedir. Oysaki, reklam ile avukatın sunacağı hizmet üzerinde talep artırma yoluna gidilmesi avukatlık mesleğinin sahip olduğu vasıflar ile bağdaşmamaktadır. Bu sebeple, avukatlık mesleğinin toplum içerisindeki güvenilirliğinin zedelenmemesi maksadıyla, meslek mensuplarına, uymak zorunda olduğu bazı yükümlülükler yüklenmekte ve yasal düzenlemelerle bazı sınırlar çizilmektedir (Akcan ve Ercan, 2003, s.83; Çelik, 2008, s.337; Çelik, 2016, s.155; Demir, 2009, s.129, Korkusuz ve Korkusuz, 2016, s.192). Bu yükümlülüklerden biri de reklam yapmama yükümlülüğü veya reklam yasağına uyma yükümlülüğüdür (Aslan, 2015, s.19; İşoğlu, 2013, s.30; Korkusuz ve ark., 2016, s. 192).

Avukatlık mesleği, serbest bir meslek olup, avukat, mesleki faaliyetlerini icra ederken bir tekele sahip olmakta, diğer meslektaşlarıyla da bir rekabet içerisine girmektedir ( Akcan ve ark, 2003, s.84; Deliduman, 2003, s.170). Avukatlık mesleğinin serbest meslek olması, her an rekabete açık olması sonucunu doğururken, meslek mensuplarını reklam yapmaya teşvik etmektedir (Akcan ve ark, 2003, s.84; Aslan, 2015, s.19; Deliduman, 2003, s.170). Aynı meslek mensubu kişilerin birbirlerini meslektaş olarak değil de rakip olarak görmeye başlamaları, rekabete yol açacak eylemleri yasaklayıcı kurallar konmasına gerekçe oluşturmaktadır (Aslan, 2015, s. 19; Güner, 2011, s.516; Erem, 1961, s. 19). Böylece rekabet anlayışından bir nebze de olsa uzaklaşmış olup, mesleğin ticarileşme faaliyeti önüne geçilmiş olunacaktır. Kamu hizmeti niteliği taşıyan avukatlık mesleğinin ticarileşmesini engellemek ve avukatların iş temini konusunda birbirleriyle aralarında bir rekabet oluşturup haksız rekabette bulunmalını engellemek adına, reklam yasağı adı altında kurallar geliştirilmiştir (Akcan ve ark, 2003, s.93; Aslan, 2015, s.71; Erem, 1961, s.19; Güner, 2011, s.517; Güner, s.398). Avukatın iş temin etmesi

19 | P a g e

www.iiste.org 
mesleki becerisiyle doğru orantılıdır. Ancak bazı avukatlar mesleki becerisiyle değil de reklam vasıtasıyla ön plana çıkmaya çalışmaktadırlar. Hal böyle olunca, meslek mensupları arasında doğan rekabet, mesleği ticarileştirmekte ve meslek anlayışını ortadan kaldırmaktadır (Aslan, 2015, s.73; Erem, 1961, s.19; Güner, s.398; Korkusuz ve ark., 2016, s.192; Sungurtekin, 2013, s.576). Reklam yasağ1 vasıtasıyla, avukatlık mesleğinin onursal olma özelliği korunmaktadır (Aslan, 2015, s.74; Sungurtekin, 2013, s.576). Reklam yasağına uyma yükümlülüğü avukatlık meslek anlayışını koruduğu kadar, yargıya olan güveni de güçlendirmektedir (Erem, 1961, s.19; Güner, s.398; Korkusuz ve ark., 2016, s. 192; Sungurtekin, 2013, s. 576). Reklam yasağının, bir diğer katkısı da avukatın müvekkiline karşı bağımsızlı̆̆ını koruyabilmesi açısından kendini göstermektedir (Akcan ve ark, 2003, s.94; Aslan, 2015, s.76; Pekcanıtez, 2016, s.658). Mesleki becerisi ile değil de reklam vasitasıyla ön plana çıkıp, iş temin eden avukattan müvekkilin beklentisi kuşkusuz çok daha fazla olacaktır. Saydığımız bu haller reklamın, avukatlık mesleğine olan olumsuz etkilerini ortaya koyarken, öte yandan reklamın toplumu bilgilendirme, yargıya olan güveni artırma, hak arayışını yargı yoluyla gerçekleştirmeye sevk etme, savunma hakkına sahip olma bilincini oluşturma veya geliştirme gibi olumlu etkileri de söz konusudur. Avukatlık mesleğini fiilen icra edenlerin salt iş elde etme ve ün kazanma maksadıyla reklam sayılabilecek her türlü eylem ve teşebbüslerini engellemek amacıyla, Kuzey Kıbris hukukunda 1981 Avukatlar Tüzüğü'nde reklam yasağına ilişkin düzenlemelere yer verilmiştir. Bu düzenlemeler, reklam yasağının kapsamını oluşturmaktadır. Avukatın reklam yasağına ilişkin benzer veya farklı düzenlemeleri, Türk hukukunda gerek Avukarlık Kanunu'nda gerek Türkiye Barolar Birliği Reklam Yasağı Yönetmeliğinde veya Meslek Kuralları içerisinde görmek mümkündür (Aydın, 2013, s.382; Çelik, 2016, s.149; Güner, 2011, s.518; İşoğlu, 2013, s.30; Korkusuz ve ark., 2016, s.192; Sungurtekin, 2006, s.282-283; Sungurtekin, 2013, s.578-579). 1981 Avukatlar Tüzüğü'nde reklam yasağ1, 13. maddede 5 fikra halinde geniş bir perpektifte ele alınmıştır. 2. 3. Ve 4. fikralar, avukatın görsel ve yazılı iletişim araçları vasıtasıyla reklam yasağı teşkil edecek faaliyetlerini düzenlemektedir.

\section{Reklam Yasağı Teşkil Eden Haller}

\subsection{Avukatın İlgili Olduğu Dava Hakkında Yazılı Basın Yolu ile Açıklama Yapması}

1981 Avukatlar Tüzğü'nün 13. maddesinin ikinci fikrasında, avukatın ilgili olduğu dava hakkında basın yoluyla açıklama yapması düzenlenmiştir. Düzenlemeye göre, bir avukat mahkemelerde askıda bulunan herhangi bir davanın veya avukat olarak bulunmuş olduğu veya halen bulunmakta olduğu, başka bir deyişle, ilgili olduğu davaya ilişkin meselenin ayrıntısı hakkında basına bilgi vermemeli veya meseleye ilişkin ayrıntının yayınlanmasına sebep olmamalı veya müsaade etmemelidir. Söz konusu düzenlemeye göre avukatın ilgili olduğu dava hakkında hiçbir şekilde basına bilgi vermemesi gerektiği sonucuna varılmaktadır. Aksi halde, avukatın ikinci fikraya aykırı davranması sebebiyle, reklam yasağının ihlali söz konusu olacaktır. Oysa avukatın, avukatlık meslek kurallarına ve sır saklama yükümlülüğüne aykırı olmamak kaydıyla, ilgili olduğu dava hakkında kamuouyuna bilgi vermesi, avukatlık mesleğinin saygınlığı ve yüceliği ile örtüşür olacaktır. Dolayısıyla bu fikrada yer alan düzenlemenin tekrardan ele alınıp, revize edilmesi gerektiği kanaatindeyiz. Türk hukukunda da TBB Reklam Yasağ1 Yönetmeliği’nin 8. maddesinin (b) bendinde de benzer bir düzenleme söz konusudur. Bu düzenlemeye göre, avukatın halen veya eskiden takip ettiği, devam eden veya sonuçlanmış bir dava hakkında davanın hukuki boyutları içinde kalmak kaydıyla ve zorunlu haller dışında yazılı iletişim araçlarına görüntü, bilgi, demeç veremeyeceği, açıklama yapamayacağı belirtilmiştir. Reklam Yasağı Yönetmeliği’nin 8. maddesinin (b) bendi, 1981 Avukatlar Tüzüğü'nün 13. maddesinin ikinci fikrasına göre, daha esnek bir düzenlemedir. Ancak, buradada avukatın ancak zorunlu hallerde, hukuki boyutlar içerisinde kalmak şartıyla, yazılı iletişim araçlarına görüntü, bilgi, demeç verebileceği, açıklama yapabileceği belirtilmiştir. Kanaatimizce her iki hukuk sisteminde yer alan bu düzenlemelerin yumuşatılması gerekmektedir. Zira avukat reklam ile sadece kendi şahsi ününü artırmamakta, bunun yanında ilgili olduğu dava ile yazılı veya görsel iletişimde yer alarak, toplumdaki kişileri savunma hakkı bakımından bilinçlendirmekte ve adalet anlayışını yaymakta, mesleğin saygınlığını ortaya koymaktadır. Elbette, görsel ve yazılı iletişimde yer alırken, bunu salt reklam faaliyeti şeklinde yerine getirmemeli, aksi halde mesleğin onurunu tehlikeye düşürecek bir tutum sergilemiş olur. Ancak kamuoyunu bilgilendirme, adalet bilincini artırma, savunma hakkını aşılama faaliyetlerinin daha ağır bastığı hallerde, herhangi bir yasaklılığın söz konusu olmaması gerektiği kanaatindeyiz.

\subsection{Avukatın Kendini Övücü İfadeler Kullanarak, Lüzumsuz Yere Resmini veya İsmini Kullanarak Basın-Yayın Organlarında Yer Alması}

Reklam yasağı kapsamında ele alabileceğimiz bir diğer hal ise, 1981 Avukatlar Tüzüğü’nün 13. maddesinin üçüncü fikrasında düzenlenmiştir. Bu düzenleme, avukatın gereksiz bir şekilde ismini kullanmaktan kaçınması, kendini övücü ifadeler kullanmaması ve fotoğrafinı teşhir etmemesi şartıyla,

20 | P a g e 
herhangi bir hukuk dergisi veya sair bir dergi veya basın-yayın organının soracağı soruları cevaplayabileceğine ilişkindir. Burada üzerinde durulması gereken husus; avukat, hukuk dergisi, başka sair dergi veya basın yayın organlarının soracağı soruları cevaplandırırken veya herhangi bir düşünceyi açıklarken salt ün kazanma iradesiyle hareket ettiği müddetçe, reklam yasağı ihlali oluşacaktır. Aksi halde, avukatın böyle bir iradesi olmadan, ismini ve resmini kullanarak basın yayın organının sorularını cevaplaması kanaatimizce, reklan teşkil etmeyecektir. Avukatın bu davranışlarının reklam yasağını ihlal edici nitelikte olup olmadığını, avukatın hangi maksatla ön plana çıktı̆ı̆ı tespit ederek, saptamamız mümkündür. Avukat, ün kazandırıcı hareketlerden kaçınıyorsa, herhangi bir düşünceyi açıklarken kamuoyunu bilgilendirme kastıyla hareket ediyorsa, kendini övücü, ön plana çıkarıcı hareketlerden kaçınıyorsa, isminden bahsetmesi veya resmini kullanması reklam yasağını ihlal edici davranış olarak nitelendirilmeyecektir. Zira avukatın niyetinin reklam olmadığı gerçekleştirdiği davranışları sayesinde kolayca anlaşılmaktadır. Aksi halde, kamuoyunu bilgilendirme maksadıyla değil de sırf fotoğrafını sergileyerek veya ismini lüzumsuz bir şekilde kullanarak ün kazanıp iş temin etme maksadına hizmet ettiğgi sonucuna varılarak, reklam yasağı ihlalinin varlı̆̆ kabul edilecektir. Benzer bir düzenlemeye TBB Reklam Yönetmeliği'nin 8. maddesinin (c) bendinde de yer verilmiştir. Şöyle ki, yönetmelik kapsamında olan kişilerin, yazıll, işitsel, görsel iletişim araçlarında ve internette röportaj, sohbet, konuşma, tartışma ve benzeri programlara katıldıkları zaman, reklama sebebiyet verecek her türlü hareketten ve avukatlık mesleğine zarar verecek her türlü açıklamalardan kaçınmak zorunda oldukları düzenlenmiştir. 1981 Avukatlar Tüzüğ̈̈’nde 13. maddenin üçüncü fikrasında da, avukatın gereksiz şekilde ismini kullanması, avukatın kendi kendini övücü hareketlerde bulunması ve sık sık resmini kullanması, reklam sayılacak davranışlar olarak kabul edilmektedir. TBB Reklam Yasağı Yönetmeliği’nin 8. Maddesinin (c) bendinde, "mesleğe zarar verici her türlü hareket ve her türlü açıklama" ifadesine yer verilerek reklam yasağı teşkil edecek davranışlar yelpazesi daha geniş tutulmuştur. Oysa, avukata mesleki bilgi ve becersini aktarabilmesi, hukuki bilgiyi en kolay şekilde muhatabına geçirebilmesi adına kendinden birşeyler anlatabilmesine ilişkin imkan verilmesi halinde, hukuki dergi, sair dergi veya basın yayın organlarının sorularına ilişkin cevaplarını paylaşması amacına uygun olacaktır.

\subsection{Avukatın Reklam Yasağı Teşkil Edecek Şekilde Hukuk Dergisi, Sair Bir Dergi veya Herhangi Bir Gazetede Hukuki, Siyasi veya Başka Bir Alanda Makale Yayımlayarak Yer Alması}

Reklam yasağına ilişkin bir diğer düzenleme 13. Maddenin dördüncü fikrasında ele alınmıştır. Dördüncü fikra, tamamen üçüncü fikrayyla bağlantılı olan bir içerik taşımaktadır. Şöyle ki, üçüncü fikrada yer alan düzenlemelerin aksine davranılmadığı müddetçe, avukatın herhangi bir gazete de, hukuk dergisi olsun veya olmasın herhangi bir dergide, hukuki, siyasi veya herhangi bir başka konuda makale yazması meslek kurallarına ve meslek onuruna bağdaşır nielikte kabul edilmektedir. Ancak avukatın, dergide makalesini yayımlarken veya gazetede köşe yazısını yayımlarken resmini kullanması, övücü ifadelerde bulunması veya ismini kullanması dördüncü fikraya göre, reklam yasağı teşkil edecek niteliktedir. Zira dördüncü fikra ile bağlantılı olan üçüncü fikrada avukatın resmini, ismini teşhir etmemesi gerektiği belirtilmişir. Oysaki avukat yayımlayacağı makale veya köșe yazısı ile meseki bilgi, deneyim ve becersini ortaya koyarken, dolaylı da olsa reklamını yapmaktadır. Dolayısıyla bu beceri ve deneyimlerini makale veya köşe yazısıyla ortaya koyan avukatın, resminin veya isminin reklam olarak buna etki ettiğini dile getirmek mantık dışıdır. Önemli olan, avukatın niyetinin ne olduğunun saptanmasıdır. Kamuoyunu bilgilendirme, hukuki bir konuya dikkat çekme, toplumu düşünmeye sevk etme, hukuki yazılarla yargıya olan güveni artırma, avukatlık mesleğinin onur ve saygınlığını aşılama gibi amaçlardan sapılarak, salt iş elde etme, para kazanma, rekabet ortamı yaratarak firsat eşitsizliği yaratma durumunda elbete, reklam yasağının ihlalinden söz etmenin mümkün olacağı kanaatindeyiz.

\section{Sonuc}

Meslek onurunun korunması ve gücünü kaybetmemesi adına, 1981 sayılı Avukatlar Tüzüğü’nde, avukatların reklama ilişkin uymakla yükümlü oldukları kurallar belirtilmiştir. Bu kurallar avukatlar arasındaki rekabeti önleyici, kamu hizmeti ve aynı zamanda serbest meslek niteliği taşıyan avukatlık mesleğini icra edecek meslek mensuplarının bağımsızlığını korumayı hedef alsa da, zaman zaman bu kurallar, avukatların faaliyet özgürlüklerini de kısitlar niteliktedir.

1981 sayılı Avukatlar Tüzüğü'nün çok eski tarihli bir düzenleme olması, reklam yasağına ilişkin kuralların zaman zaman eksik olması, belirgin olmaması, teknolojik gelişmelerin gerisinde kaldığı da gözden kaçmamaktadır. Kanaatimizce, modern çağın gerekleri dikkate alınarak, yeni düzenlemelere veya varolan düzenlemelerin günümüz ihtiyaçlarına öre revize edimesi gerekmektedir. 


\section{Kaynaklar}

Akcan R., Ercan İ. Avukatlıkta Reklam Yasağı, [Online]: http://hukuk.marmara.edu.tr.

Aslan Ç.(2015). Avukatlık Hukukunda Reklam Yasağı, İstanbul.

Aydın N.(2013). Avukatın Hak ve Sorumluluklar, [Online]: http://www.muharrembalci.com.

Çelik L.(2016). Avukatlık Meslek Kuralları, Ankara.

Çelik L.(2008). Meslek Kuralları'nda Avukatın Reklam Yasağı, Türkiye Barolar Birliği Dergisi, Say1.78, 337-351.

Deliduman S.(2003). İnternet Üzerinden Avukatlık ve Reklam Yasağı, Prof. Dr. Ergün Önen' Armağan, İstanbul, s.169-180.

Demir Ş. (2009). Avukatların Reklam Yasağı Nasıl Olmalı?, Ankara Barosu Dergisi, Y11. 67, Sayı 4, 127-133.

Erem F.(1961) Reklam Yasağı, Türkiye Barolar Birliği Dergisi, Sayı 1, 16-26.

Ersoy Y. (2004). Avukatlıkta Reklam Yasağı, Ankara Barosu Hukuk Kurultayı, 203-229.

Güner S.(2011). Avukatlık Hukuku, Ankara.

Güner S. “Avukatlık Mesleğinin Tarihçesi”, [Online]: http://www.muharrembalci.com.

İşoğlu P.(2013). Avukatlık ve Kalem Mevzuatı, Adana.

Korkusuz R., Korkusuz H.(2016). Avukatlık Hukukuna Giriş, Bursa.

Meral S. (2006). Kurumsal Reklam Kavramı ve Bankacılık Sektöründeki Kurumsal Reklam Örnekleri, II.Ulusal Halkla İlişkiler Sempozyumu.

Onay A.(2012). Reklamlara Yönelik Tutumlar, Gümüşhane Üniversitesi İletişim Fakültesi Elektronik Dergisi, Cilt 1, Say1,4, 51-66.

Özdemir H.(2004). Aldatıcı Reklamlara Karşı Tüketicinin Korunması, Ankara Üniversitesi Hukuk Fakültesi Dergisi, Cilt 53, Sayı 3, 61-90.

Pekcanıtez H.(2016). Avukatlık Sözleşmesi, Makaleler Cilt I, İstanbul.

Peker, Ö.L.(2007). Avrupa Birliği ve Türk Hukukunda Avukatlık Ortaklığı, (Yayımlanmamış Doktora Tezi), Selçuk Üniversitesi Sosyal Bilimler Enstitüsü, Konya.

Rumpf C. (2010). Türk Hukuku ile Mukayese Edildiğinde Almanya'da ve Avrupa'da Avukatların Reklam Yapma Hakk1, Ankara Barosu Dergisi, Y11, 68 Sayı: 2010/1, 145-166.

Sungurtekin M. (2006). Avukatlık Hukuku, İzmir.

Sungurtekin M. (2013). Avukatlık Mesleği, İzmir.

Yavaş M. (2016). Türk Hukukunda Avukatın Reklam Yasağı, Marmara Üniversitesi Hukuk Fakültesi Hukuk Araştırmaları Dergisi, Cilt 21, Sayı 2, 727 - 740. 